\title{
Mixed Adenoneuroendocrine Carcinoma: A Case Report
}

\author{
Manas Madan ${ }^{1}$, Pavneet Bhatia ${ }^{2}$, Manisha Sharma ${ }^{3}$, Mridu Manjari $^{4}$
}

\begin{abstract}
Introduction: Mixed adenoneuroendocrine carcinoma (MANEC) is a rare tumor of the gastrointestinal tract which consists of a dual adenocarcinomatous and neuroendocrine differentiation, each component representing at least $30 \%$ of the tumor.

Case description: A 60-year-old women presented with complaint of upper abdominal pain and difficulty in swallowing solid food. Endoscopy revealed linitis plastica. Contrast-enhanced computed tomography abdomen revealed a diffuse stomach wall thickening in region of fundus and body with enhancing nodular lesions likely mitotic etiology along with upper abdominal lymphadenopathy. Patient underwent total gastrectomy. Grossly there was a grey white growth at the antrum measuring $3.5 \times 2 \mathrm{~cm}$ in size with multiple satellite nodules. Histopathological report revealed tumor cells, forming glandular pattern. Amidst these there was also present a second population of small monomorphic cells forming insular pattern. Twenty out of 25 lymph nodes showed secondary carcinomatous deposits. Diagnosis of MANEC was proposed which was confirmed on immunohistochemistry with immunopositivity for synaptophysin/chromogranin and immunonegativity for CK7/CK20/CEA. Patient received chemotherapy and 25 cycles of radiotherapy but presented again with hepatic deposits within 6 months.

Conclusion: The case is worth reporting because of its rare presentation. Close attention should be paid to such patients, as MANEC can be a highly aggressive tumor, showing rapid progression and metastasis.

Keywords: Adenoneuroendocrine carcinoma, Immunohistochemistry, Linitis plastic.

AMEI's Current Trends in Diagnosis \& Treatment (2020): 10.5005/jp-journals-10055-0088
\end{abstract}

\section{INTRODUCTION}

Mixed adenoneuroendocrine carcinoma (MANEC) introduced by the World Health Organization is a rare tumor of the gastrointestinal tract, which consists of a dual adenocarcinomatous and neuroendocrine differentiation, each component representing at least $30 \%$ of the tumor. ${ }^{1}$ Owing to its rarity, MANEC has been presented only as a case report, with only a few cases reported till date and with its treatment being unclear. This kind of neoplasm has a poor prognosis, as both components are malignant with high proliferative capacity and early vascular invasion leading to multiple organ metastases. ${ }^{2}$ Here, a rare case of gastric MANEC treated with gastrectomy,chemotherapy, and radiotherapy is presented.

\section{Case Description}

A 60-year-old female presented with complaints of upper abdominal pain and difficulty in swallowing solid food, which later progressed to liquid diet. Endoscopy revealed linitis plastica. Contrast-enhanced computed tomography of abdomen revealed a diffuse stomach wall thickening in the region of fundus and body with enhancing nodular lesions likely of mitotic etiology along with upper abdominal lymphadenopathy. The patient underwent total gastrectomy. Grossly, there was a gray white growth at the antrum along with wall thickening measuring $3.5 \times 2 \mathrm{~cm}$ in size, $5 \mathrm{~cm}$ away from the distal (pyloric end) (Fig. 1A). Multiple satellite nodules were also found, the largest measuring $1 \mathrm{~cm}$ in diameter, distributed throughout the stomach, reaching up to and involving a fundic surgical margin. Twenty five lymph nodes were recovered, and the histopathological report revealed tumor cells, forming a glandular pattern. These cells were round to oval, showing hyperchromatism and pleomorphism and a moderate amount of cytoplasm. Mitotic activity was increased (Fig. 1B). Amidst these, there was also a second population of small monomorphic cells present forming
${ }^{1-4}$ Department of Pathology, Sri Guru Ram Das Institute of Medical Sciences and Research, Amritsar, Punjab, India

Corresponding Author: Manas Madan, Department of Pathology, Sri Guru Ram Das Institute of Medical Sciences and Research, Amritsar, Punjab, India, Phone: +91 9815963778, e-mail: manasmadaan@gmail. com

How to cite this article: Madan M, Bhatia $P$, Sharma $M$, et al. Mixed Adenoneuroendocrine Carcinoma: A Case Report. AMEl's Curr Trends Diagn Treat 2020;4(1):38-40.

Source of support: Nil

Conflict of interest: None

an insular pattern (Fig. 1C). Tumor cells with a glandular pattern were seen infiltrating into the muscle (Fig. 1D) as well as breaching the serosa. About 20 out of 25 lymph nodes showed secondary carcinomatous deposits. On immunohistochemistry, the carcinoid element comprised approximately $70 \%$ of the tumor with the adenocarcinoma element comprising approximately $30 \%$ as seen on the sections. The tumor proved to be adenocarcinoid of the stomach with synaptophysin/chromogranin positivity. The CK7/ CK20/CEA and CDX2 were negative with ki67 proliferative index of $40 \%$. The patient received chemotherapy with 25 cycles of radiotherapy but presented again with hepatic deposits within 6 months.

\section{Discussion}

Neuroendocrine cell carcinoma is sometimes associated with adenocarcinoma, classified as "MANEC" in the 2010 World Health Organization guidelines. ${ }^{1}$ There are several different forms of stomach cancers, the most common being adenocarcinomas, gastric lymphomas, and gastrointestinal stromal tumor.

() The Author(s). 2020 Open Access This article is distributed under the terms of the Creative Commons Attribution 4.0 International License (https://creativecommons. org/licenses/by-nc/4.0/), which permits unrestricted use, distribution, and non-commercial reproduction in any medium, provided you give appropriate credit to the original author(s) and the source, provide a link to the Creative Commons license, and indicate if changes were made. The Creative Commons Public Domain Dedication waiver (http://creativecommons.org/publicdomain/zero/1.0/) applies to the data made available in this article, unless otherwise stated. 

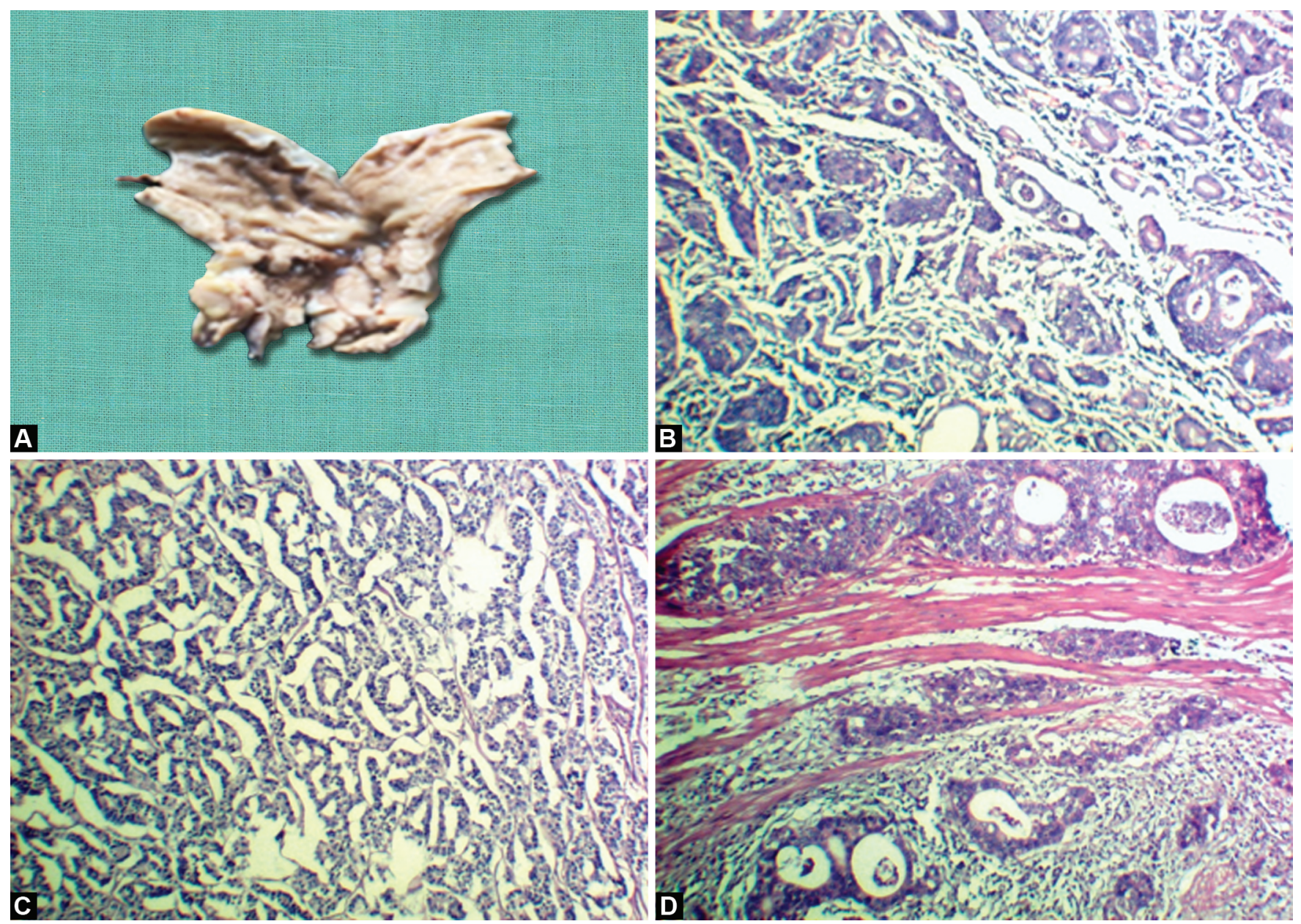

Figs 1A to D: (A) Gross exhibiting thickened wall with a nodular growth in the antrum and satellite nodules; (B) Microscopically exhibiting adeno pattern ( $\mathrm{H}$ and $\mathrm{E} ; 100 \times)$; (C) Microscopically exhibiting insular pattern ( $\mathrm{H}$ and E; 100X); (D) Microscopically exhibiting muscular invasion (adeno component) (H and $\mathrm{E} ; 100 \times)$

Mixed adenoneuroendocrine carcinoma is a rare tumor of the gastrointestinal tract. The average age of patients is $59.3 \pm 10.9$, with the male-to-female ratio being $2.4: 1$ or greater, ${ }^{3,4}$ and the patient in this case report was also a 60-year-old female. The common features observed are nausea, vomiting, heartburn, indigestion, loss of appetite, abdominal fullness, weight loss, and fatigue. According to some authors, the clinical behavior depends on the grade of the neuroendocrine component, whereas others reveal that the characterstics of adenocarcinoma influence the outcome in well-differentiated neuroendocrine components. Our patient had ki67 proliferative index of $40 \%$. Although the patient received chemotherapy with 25 cycles of radiotherapy, she reported back within 6 months with hepatic deposits. This indicates that MANEC is a highly aggressive tumor showing rapid progression, as it is known to frequently invade the lymphatic and vascular lumens and subsequently metastasize to the lymph nodes and liver, even during the early stages. As evident in the present case, 20 out of 25 lymph nodes showed secondary carcinomatous deposits. The disease-free period is usually short in these cases (Fig. 2).

The assessment of MANEC is still incomplete, because the results of the studies conducted before 2010 did not reflect the exact definition. However, MANECs containing a poorly differentiated NEC component should be treated as NECs. Nevertheless, intense follow-up for possible recurrence is necessary, as the disease can lead to poor prognosis. In the recent studies carried out, chemotherapy has been reported to be the treatment of choice, which had improved the median survival to the range of 6-12 months. Although it has not been standardized, a combination of etoposide and cisplatin is used. Even though the role of radiation for MANEC is unclear, local radiations can be given to reduce the risk of local recurrence. After surgery with chemotherapy and radiotherapy to the tumor region, the patient may have a long-term disease-free survival.

\section{Conclusion}

The case of MANEC stomach with hepatic deposits presented with a rare presentation of dysphagia. Close attention should be paid to such patients as MANEC can be a highly aggressive tumor showing rapid progression. In the treatment of MANEC, it is necessary to keep the patient under constant observation to diagnose any further metastasis as early as possible, as the disease-free period is usually short. The prognosis depends on the early diagnosis and treatment, and hence all efforts should be made to diagnose this aggressive tumor at an early stage. 


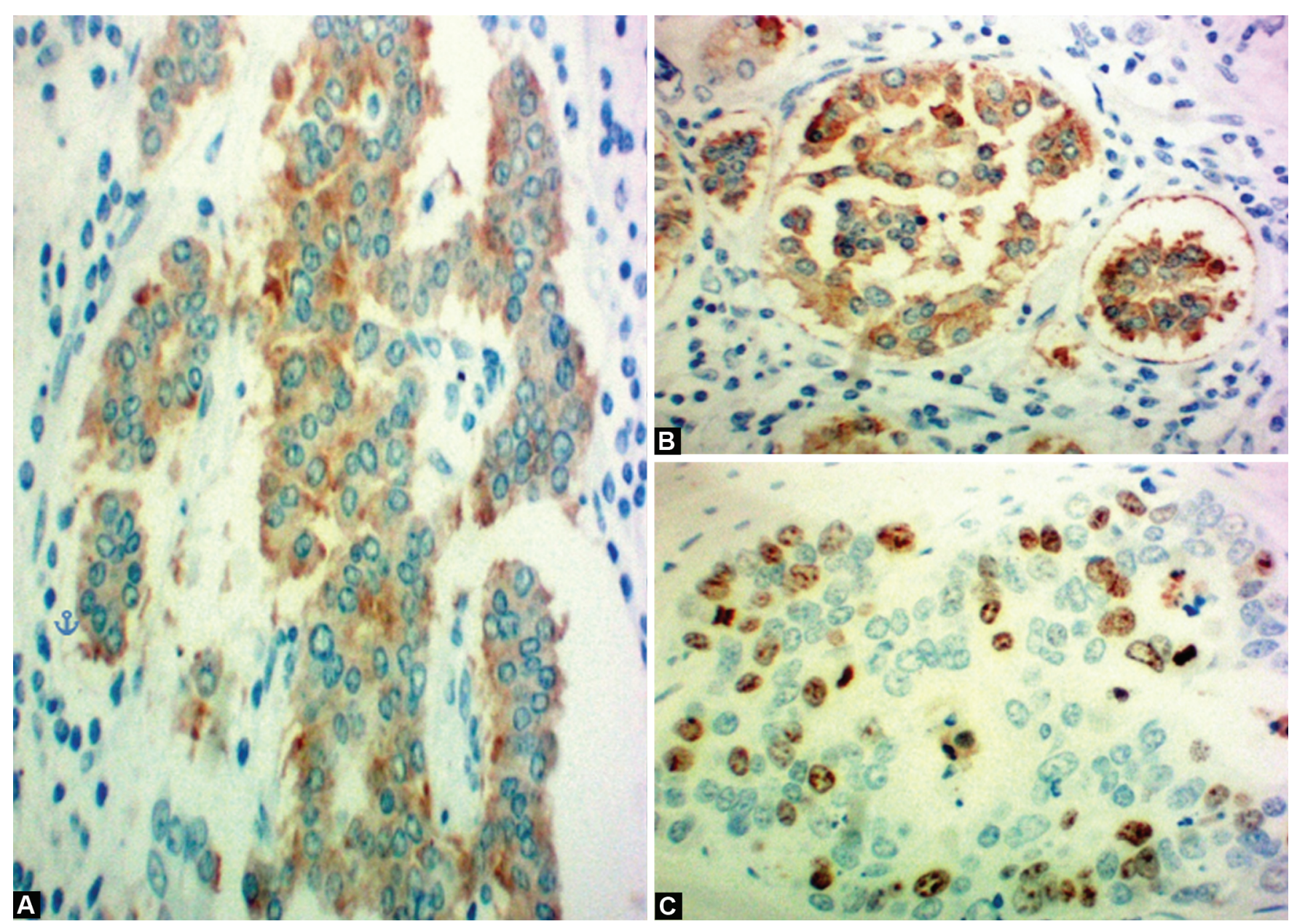

Figs $2 A$ to C: (A) Synaptophysin positivity (IHC; 400X); (B) Chromogranin positivity (IHC; 400X); (C) Ki67 positivity (IHC; 400X)

\section{References}

1. Rindi G, Klimstra DS, Arnold R, et al. Nomenclature and classification of neuroendocrine neoplasms of the digestive system. In: Bosman FT, Carneiro F, Hurban RH, et al., ed. WHO Classification of Tumours of the Digestive System. 4th ed., Lyon, France: IRAC Press; 2010. pp.13-14.

2. Otsuka M, Kato Y. Clinicopathological study of poorly differentiated and undifferentiated carcinoma of the large intestine: classification and special reference to the endocrine cell carcinoma. Nihon Syokakigeka Gakkaizasshi 1992;25(5):1248-1256.

3. Kim BS, Park YS, Yook JH, et al. Differing clinical courses and prognosis in patients with gastric neuroendocrine tumours based on the 2010WHO classification scheme. Medicine (Baltimore) 2015;94(44):e1748. DOI: 10.1097/MD.0000000000001748.

4. Wu QQ, Qiang WG, Wang $F$, et al. Management of primary gastric small cell carcinoma in china. Int J Clin Exp Med 2015;8(2):1589-1597. 